\title{
NUMERICAL INVESTIGATION OF HEAT AND MASS TRANSFER INSIDE A WET COOLING TOWER
}

\author{
Paolo BLECICH, Tomislav SENČIĆ, Igor WOLF, Igor BONEFAČIĆ
}

\begin{abstract}
This paper presents a numerical investigation of heat and mass transfer inside a wet cooling tower with forced air draft, which find application in energy process industries and oil refineries. The mathematical model consists of mass, momentum and energy conservation equations, water droplet trajectories and their interaction with the gas phase, the computational domain and boundary conditions. Numerical distributions of air velocity, air temperatures, water vapor fractions and evaporation rates are shown and discussed. The wet cooling tower achieves an efficiency of around $80 \%$, which can be improved by optimizing the value of the water droplet size, nozzle spray angle and water-to-air flow rate ratio. The water droplet size has a dominant effect on the cooling tower efficiency, whereas small droplets improve the efficiency up to $10 \%$. On the other hand, the spray angle and the water-to-air ratio lead to slight improvements, about 2-3\% in the best case.
\end{abstract}

Keywords: cooling tower; forced air draft; latent heat transfer; numerical modeling; water evaporation

\section{INTRODUCTION}

A cooling tower is a device that transfers waste heat from the warmer working fluid (usually water) into the colder ambient air (atmosphere). Cooling towers find numerous applications, such as in the energy and chemical process industries, in oil refineries, thermal power plants, in heating and air-conditioning systems for buildings [1-2]. The principal parts of a cooling tower are: the reinforced concrete shell, air intake and air discharge sections, mechanical fans with motors, warm water distribution system with spray nozzles, cold water collection basin, PVC filling (exchange surface), and drift eliminator. Cooling towers replace watercooled heat exchangers when large bodies of water are not available nearby, or their use would be economically or environmentally unsustainable.

Depending on the heat transfer method, two main types of cooling towers exist [3]. In the first type, dry cooling towers, heat transfer occurs only by convection. The water stream is cooled to near the dry-bulb temperature of air. This is achieved by physically separating the water stream from the ambient air with heat exchanging surfaces. Wet cooling towers, on the other hand, work with the principle of evaporative cooling. The water stream is sprayed into the air stream, which allows for both sensible and latent heat transfer. Here, the water stream is cooled to near the wet-bulb temperature of air, which is lower than the dry-bulb temperature, thus making wet cooling towers more efficient.

Heat transfer can be intensified by mechanical air draft, where power-driven fans increase the airflow, unlike natural air draft where the airflow is buoyancy-induced [4]. Mechanical fans are placed either at the air intake side (forced draft) or at the air discharge side (induced draft). With respect to the flow arrangement between air and water streams, there are crossflow, counterflow and parallelflow cooling towers. Cooling towers with counterflow arrangement, where the air flow is opposite to the water flow, generally achieve superior efficiency.
The heat and mass transfer processes in different types of cooling towers have been subject of extensive scientific research. These studies include experimental and numerical investigations of thermal and hydraulic performance of mechanical air draft wet cooling towers with counterflow [5], parallelflow [6], and crossflow arrangements [7, 8], as well as natural air draft dry cooling towers with adjacent Savonius turbines [9], solar preheating of the airflow [10], water redistribution systems [11], water systems with vertical and horizontal spray nozzles [12]. All of these solutions aim to increase the cooling tower efficiency.

This paper analyses the heat and mass transfer phenomena inside a wet cooling tower with forced air draft and counterflow arrangement between air and water stream. The scientific contribution of this study is in the application of the porous zone model with appropriate sink terms for the momentum conservation equations in the mathematical model of the cooling tower. This is a novel approach for the treatment of heat and mass transfer in the filling of the cooling tower. Furthermore, the numerical analysis expands the study about the parameters affecting the cooling tower performance, such as the water droplet size, the water-to-air ratio and the nozzle spray angle. The analyzed cooling tower is part of the cooling tower system in the fuel refinery INA Rijeka (Urinj) [13, 14].

\section{MATHEMATICAL MODEL 2.1 Approach}

The numerical modeling approach includes the choice of a suitable mathematical model. The mathematical model consists of mass, momentum and energy conservation equations, and of the equations describing the trajectories of the discrete phase (water droplets) and their interaction with the continuous phase (air), as well as of the cooling tower computational domain with the boundary conditions. The numerical analysis of heat and mass transfer in the cooling tower is carried using the computer software ANSYS Fluent. 
The computational domain is discretized with the finite volume method while the unknown quantities at the finite volume boundaries are calculated using the second order upwind scheme [15]. The coupling between the flow velocity field and the pressure field is performed by the SIMPLE algorithm.

\subsection{Computational Domain}

The cooling tower studied in this paper is a model representation of the real cooling tower, which operates as one in the eight-unit cooling tower system of the INA fuel refinery, shown in Fig. 1. The real cooling tower contains 192 water nozzles, which would be unpractical to model all numerically. To facilitate the numerical analysis, the real cooling tower was downsized 16 times in terms of the number of nozzles. Thus, the numerical cooling tower contains only 12 nozzles and one-sixteenth of the air and water mass flow rates. Nevertheless, the water-to-air mass flow rate remains equal, which ensures the validity of this approach. The computational domain is chosen taking into account the geometry of the real cooling tower, its physical phenomena but also the available computer resources. The two-dimensional cross-section of the cooling tower is identified as the computational domain since the airflow is two-axis dominant, as shown in Figure 2. The domain is meshed with 465000 quadrilateral finite volumes and the average size of which is $4 \mathrm{~cm}^{2}$.

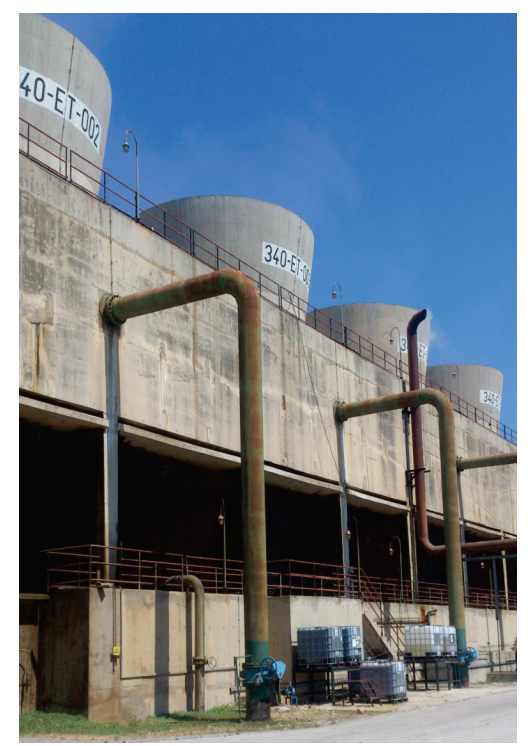

Figure 1 The cooling towers of the INA fuel refinery. At the forefront: water supply pipes and air intake.

\subsection{Conservation Equations}

The air flow in the cooling tower is modeled using the steady-state turbulent model. The system of partial differential equations include mass, momentum and energy conservation for two-dimensional steady-state turbulent airflow in the cooling tower. Their solutions yield the flow velocity, pressure and temperature fields in the cooling tower. The mass conservation equation reads

$$
\frac{\partial\left(\rho w_{\mathrm{x}}\right)}{\partial x}+\frac{\partial\left(\rho w_{\mathrm{y}}\right)}{\partial y}=0
$$

The momentum conservation (Navier-Stokes) equations are

$$
\begin{aligned}
& \frac{\partial\left(\rho w_{\mathrm{x}} w_{\mathrm{x}}\right)}{\partial x}+\frac{\partial\left(\rho w_{\mathrm{x}} w_{\mathrm{y}}\right)}{\partial y}=\frac{\partial}{\partial x}\left(\eta \frac{\partial w_{\mathrm{x}}}{\partial x}\right)+\frac{\partial}{\partial y}\left(\eta \frac{\partial w_{\mathrm{x}}}{\partial y}\right)-\frac{\partial p}{\partial x}+S_{\mathrm{M}_{\mathrm{x}}} \\
& \frac{\partial\left(\rho w_{\mathrm{y}} w_{\mathrm{x}}\right)}{\partial x}+\frac{\partial\left(\rho w_{\mathrm{y}} w_{\mathrm{y}}\right)}{\partial y}=\frac{\partial}{\partial x}\left(\eta \frac{\partial w_{\mathrm{y}}}{\partial x}\right)+\frac{\partial}{\partial y}\left(\eta \frac{\partial w_{\mathrm{y}}}{\partial y}\right)-\frac{\partial p}{\partial y}-\rho g+S_{\mathrm{M}_{\mathrm{y}}}
\end{aligned}
$$

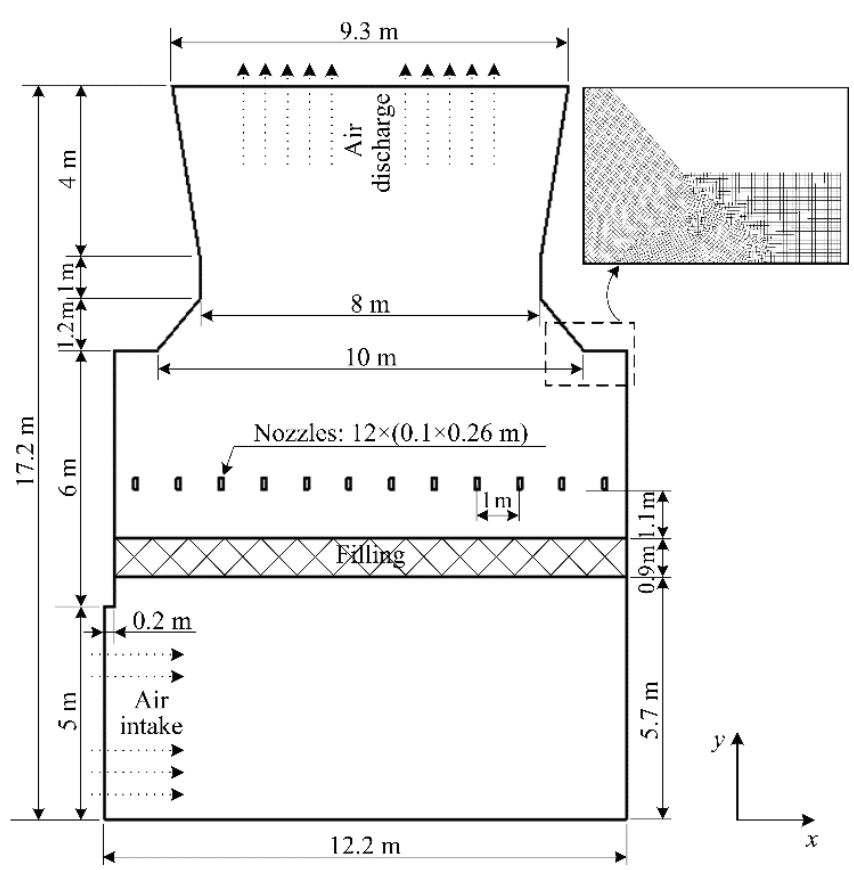

Figure 2 The computational domain with a meshing detail

The air flow in the cooling tower is turbulent and the velocity components $\left(w_{\mathrm{x}}\right.$ and $\left.w_{\mathrm{y}}\right)$ are expressed as sums of their mean $\left(\bar{w}_{\mathrm{x}}\right.$ and $\left.\bar{w}_{\mathrm{y}}\right)$ and fluctuating terms ( $w_{\mathrm{x}}{ }^{\prime}$ and $\left.w_{\mathrm{y}}{ }^{\prime}\right)$. Therefore, additional equations are necessary for each of the momentum conservation equations. In the standard $k-\varepsilon$ turbulence model, the equations for the turbulence kinetic energy $(k)$ and its rate of dissipation $(\varepsilon)$ are

$$
\begin{aligned}
& \frac{\partial}{\partial x_{\mathrm{i}}}\left(\rho \bar{w}_{\mathrm{i}} k\right)=\frac{\partial}{\partial x_{\mathrm{j}}}\left[\left(\eta+\frac{\eta_{\mathrm{t}}}{\sigma_{\mathrm{k}}}\right) \frac{\partial k}{\partial x_{\mathrm{j}}}\right]-\rho\left[\overline{w_{\mathrm{i}}^{\prime} w_{\mathrm{j}}^{\prime}} \frac{\partial \bar{w}_{\mathrm{j}}}{\partial x_{\mathrm{i}}}-\varepsilon\right] \\
& \frac{\partial}{\partial x_{\mathrm{i}}}\left(\rho \bar{w}_{\mathrm{i}} \varepsilon\right)=\frac{\partial}{\partial x_{\mathrm{j}}}\left[\left(\eta+\frac{\eta_{\mathrm{t}}}{\sigma_{\varepsilon}}\right) \frac{\partial \varepsilon}{\partial x_{\mathrm{j}}}\right]-\rho\left[\overline{w_{\mathrm{i}}^{\prime} w_{\mathrm{j}}^{\prime}} \frac{\partial \bar{w}_{\mathrm{j}}}{\partial x_{\mathrm{i}}} C_{1 \varepsilon}-\varepsilon C_{2 \varepsilon}\right] \frac{\varepsilon}{k}
\end{aligned}
$$

The Boussinesq hypothesis gives the relationship between Reynolds stresses and the mean velocity gradients as

$$
-\rho \overline{w_{\mathrm{i}}^{\prime} w_{\mathrm{j}}^{\prime}}=\eta_{\mathrm{t}}\left(\frac{\partial \bar{w}_{\mathrm{i}}}{\partial x_{\mathrm{j}}}+\frac{\partial \bar{w}_{\mathrm{j}}}{\partial x_{\mathrm{i}}}\right)-\frac{2}{3} \rho k \delta_{\mathrm{ij}}
$$


The turbulent (eddy) viscosity is calculated as

$$
\eta_{\mathrm{t}}=\frac{\rho C_{\mu} k^{2}}{\varepsilon}
$$

The model constants in the standard $k$ - $\varepsilon$ turbulence model are the following: $C_{1 \varepsilon}=1.44, C_{2 \varepsilon}=1.92, C_{\mu}=0.09, \sigma_{\mathrm{k}}=1.0, \sigma_{\varepsilon}$ $=1.3$. Heat transfer in the continuous phase (air) of the cooling tower is described by the energy conservation equation, i.e.

$$
\frac{\partial\left(\rho w_{\mathrm{x}} T\right)}{\partial x}+\frac{\partial\left(\rho w_{\mathrm{y}} T\right)}{\partial y}=\frac{\partial}{\partial x}\left(\frac{\lambda_{\infty}}{c_{\mathrm{p}}} \frac{\partial T}{\partial x}\right)+\frac{\partial}{\partial y}\left(\frac{\lambda_{\infty}}{c_{\mathrm{p}}} \frac{\partial T}{\partial y}\right)+S_{\mathrm{q}}
$$

The above conservation equations are complemented with equations for the water droplets trajectories and the heat and mass transfer between water droplets and air. The tracking of water droplets in the gas phase is specified using the Lagrangian approach [15]. The equation that describes the water droplet trajectory is an equilibrium equation for forces acting on droplets. The droplet velocity depends on aerodynamic resistance, gravity and pressure gradients, i.e.

$$
\frac{\mathrm{d} w_{\mathrm{p}, \mathrm{j}}}{\mathrm{d} t}=\frac{3}{4} \frac{C_{\mathrm{D}}}{d_{\mathrm{p}}} \frac{\rho}{\rho_{\mathrm{p}}}\left(w_{\mathrm{j}}-w_{\mathrm{p}, \mathrm{j}}\right)^{2}+\frac{g_{\mathrm{j}}\left(\rho_{\mathrm{p}}-\rho\right)}{\rho_{\mathrm{p}}}+\frac{\rho}{\rho_{\mathrm{p}}} w_{\mathrm{p}, \mathrm{j}} \frac{\mathrm{d} w_{\mathrm{j}}}{\mathrm{d} x_{\mathrm{j}}}
$$

In Eq. (9), the variables related to the water droplets are the velocity $w_{\mathrm{p}}$, the density $\rho_{\mathrm{p}}$ and the droplet diameter $d_{\mathrm{p}}$ while those describing the gas phase are the velocity $w$ and the density $\rho$. The aerodynamic drag coefficient of the droplets is denoted with $C_{\mathrm{D}}$. The turbulent dispersion of water droplets in the gas phase is described by the stochastic discrete random walk model, which takes into account the effect of turbulent fluctuations on droplet trajectories. The energy conservation equation for water droplets describes the heat transfer mechanisms between the discrete phase and the continuous phase. The change in heat content of a water droplet due to convective, radiative and evaporative heat transfer is given by

$$
m_{\mathrm{p}} c_{\mathrm{p}} \frac{\mathrm{d} T_{\mathrm{p}}}{\mathrm{d} t}=\alpha A_{\mathrm{p}}\left(T_{\infty}-T_{\mathrm{p}}\right)+\varepsilon_{\mathrm{p}} A_{\mathrm{p}} \sigma\left(T_{\mathrm{R}}^{4}-T_{\mathrm{p}}^{4}\right)+r \frac{\mathrm{d} m_{\mathrm{p}}}{\mathrm{d} t}
$$

Eq. (10) defines the quantity of heat transferred from water droplets into the gas phase, which is also the heat source term $S_{\mathrm{q}}$ in Eq. (8). In Eq. (10), the other variables are as follows: the water droplet mass $m_{\mathrm{p}}$, its heat capacity $c_{\mathrm{p}}$, surface area $A_{\mathrm{p}}$ and emissivity $\varepsilon_{\mathrm{p}}$, the air temperature $T_{\infty}$, the heat transfer coefficient $\alpha$, the radiation constant $\sigma$, and the temperature $T_{\mathrm{R}}$. Dalton's law of evaporation defines the rate of mass transfer from water droplets to the gas phase

$$
\frac{\mathrm{d} m_{\mathrm{p}}}{\mathrm{d} t}=-k_{\mathrm{m}}\left(C_{\mathrm{g}}-C_{\infty}\right) A_{\mathrm{p}} M_{\mathrm{w}}
$$

In Eq. (11), the evaporation rate depends on the mass transfer coefficient $k_{\mathrm{m}}$, the difference in vapor concentration at the droplet surface and in the gas phase $\left(C_{\mathrm{g}}-C_{\infty}\right)$, the droplet surface area $A_{\mathrm{p}}$, and the molar mass of water vapor $M_{\mathrm{w}}$. The vapor concentrations are calculated from the ideal gas law. The partial pressure of vapor at the droplet surface is equal to the saturated pressure $\left(p_{\mathrm{g}}=p_{\mathrm{s}}\right)$ at the droplet temperature $T_{\mathrm{p}}$, while the partial pressure in the gas phase is determined by Dalton's law of partial pressures $\left(p_{\infty}=r_{\mathrm{v}} \cdot p\right)$

$$
C_{\mathrm{g}}=\frac{p_{\mathrm{g}}}{R T_{\mathrm{p}}}, \quad C_{\infty}=\frac{r_{\mathrm{v}} p}{R T_{\infty}}
$$

The heat and mass transfer coefficients $\alpha$ and $k_{\mathrm{m}}$, in Eqs. (10)-(11), are determined by the Ranz-Marshall correlations [16] for the Nusselt $(\mathrm{Nu})$ and the Sherwood $(\mathrm{Sh})$ number

$$
\begin{aligned}
& N u=\frac{\alpha d_{\mathrm{p}}}{\lambda}=2+0.6 \operatorname{Re}_{\mathrm{d}}^{1 / 2} \operatorname{Pr}^{1 / 3} \\
& S h=\frac{k_{\mathrm{m}} d_{\mathrm{p}}}{D_{\mathrm{m}}}=2+0.6 R e_{\mathrm{d}}^{1 / 2} S c^{1 / 3}
\end{aligned}
$$

Above, $D_{\mathrm{m}}$ is the diffusion coefficient of water vapor in the gas phase, $\lambda$ is the thermal conductivity of air, and the dimensionless quantities are the Reynolds $(R e)$, Prandtl $(P r)$ and Schmidt $(S c)$ numbers. The filling of the cooling tower, which increases the contact surface between water droplets and air, is modeled using the porous zone model. The turbulent flow in the cooling tower filling is described by Eqs. (1)-(8) with the addition of momentum sink terms $S_{\mathrm{Mx}}$ and $S_{\mathrm{My}}$. The momentum sink terms consist of a viscous loss term and an inertial loss term, that is

$$
S_{\mathrm{M}_{\mathrm{i}}}=-\left(C_{1} \eta w_{\mathrm{i}}+C_{2} \rho w_{\mathrm{i}}^{2}\right)
$$

The coefficients for the two loss terms are derived from the Ergun semi-empirical correlation [17]

$$
C_{1}=\frac{150(1-\sigma)^{2}}{\varphi^{2} d_{\mathrm{el}}^{2} \sigma^{3}}, \quad C_{2}=\frac{1.75(1-\sigma)}{\varphi d_{\mathrm{el}} \sigma^{3}}
$$

The filling comprises 1440 elements made of hard PVC and of thickness $0.2 \mathrm{~mm}$. The dimension of each element is $1.2 \times 0.3 \times 0.3 \mathrm{~m}$. Its mass and surface area per unit of volume are $36 \mathrm{~kg} / \mathrm{m}^{3}$ and $243 \mathrm{~m}^{2} / \mathrm{m}^{3}$, respectively. The porosity is $\sigma$ $=0.97$, the characteristic length of the element is $d_{\mathrm{el}}=50 \mathrm{~cm}$ and its sphericity $\varphi=0.002$. Returning these quantities into (16), the values of the loss terms coefficients are $C_{1}=147917$ $\mathrm{m}^{-2}$ and $C_{2}=58 \mathrm{~m}^{-1}$. In the subdomain of the cooling tower filling, the effective thermal conductivity $\left(\lambda_{\mathrm{ef}}\right)$ replaces the thermal conductivity of air $\left(\lambda_{\infty}\right)$. It is obtained by averaging the thermal conductivities of the filling material $\left(\lambda_{\mathrm{s}}\right)$ and air over the filling porosity, that is 
$\lambda_{\mathrm{ef}}=\sigma \lambda_{\infty}+(1-\sigma) \lambda_{\mathrm{s}}$

\subsection{Boundary Conditions}

At the air intake of the cooling tower, air mass flow rate, air temperature and participants' mass fractions are defined. The air mass flow rate is $31.75 \mathrm{~kg} / \mathrm{s}$ and the velocity vector is normal to the inlet cross section. The inlet air temperature and relative humidity are $302 \mathrm{~K}$ and $60 \%$, whereas the wet bulb temperature is $296 \mathrm{~K}$. The mass fractions of species in the inlet air are nitrogen 0.755 , oxygen 0.23 and water vapor 0.015 . The physical properties of air are calculated by interpolating the physical properties of the individual participants. The density is calculated with the incompressible ideal gas state equation. The dynamic viscosity is determined by the three coefficients method of Sutherland's law. The boundary condition of pressure outlet is applied at the air discharge, ensuring good solution convergence in case of backflow or recirculation. The walls of the cooling tower shell are adiabatic since the heat exchange with the environment is negligible compared to the heat transfer inside the cooling tower. The warm water mass flow rate is $26.16 \mathrm{~kg} / \mathrm{s}$ and the inlet water temperature is 311 $\mathrm{K}$. The water flow rate is uniformly distributed into 12 nozzles that eject water droplets with a spray angle of $135^{\circ}$, counterflow to the air flow. The spray nozzles are modeled as discrete phase injections and their positions in the cooling tower are shown in Fig. 2. The Rosin-Rammler function describes the size distribution of water droplets, with userdefined values for the range of droplet diameters. The minimum, mean and maximum diameters in the RosinRammler distribution are $1 \mathrm{~mm}, 1.5 \mathrm{~mm}$ and $2 \mathrm{~mm}$, respectively. The material of the tower filling is high-density PVC with the following properties: density $\rho_{\mathrm{s}}=1300 \mathrm{~kg} / \mathrm{m}^{3}$, specific heat capacity $c_{\mathrm{s}}=900 \mathrm{~J} / \mathrm{kgK}$, thermal conductivity $\lambda_{\mathrm{s}}$ $=0.19 \mathrm{~W} / \mathrm{mK}$. In the filling, a constant temperature of $311 \mathrm{~K}$ is assumed while the heat transfer coefficient of $40 \mathrm{~W} / \mathrm{m}^{2} \mathrm{~K}$ is determined from (11) taking an air velocity of $2.3 \mathrm{~m} / \mathrm{s}$. The effective thermal conductivity in the filling subdomain is calculated with (17).

\section{RESULTS AND ANALYSIS \\ 3.1 Numerical Field Data}

The following results are shown for a wet cooling tower with an air mass flow rate of $31.75 \mathrm{~kg} / \mathrm{s}$ and a water flow rate of $26.16 \mathrm{~kg} / \mathrm{s}$, which returns a water-to-air flow rate ratio of 0.824 . The air temperature and relative humidity at the intake are $29{ }^{\circ} \mathrm{C}$ and $60 \%$. The wet bulb air temperature is $23{ }^{\circ} \mathrm{C}$. Warm water is supplied at a temperature of $38^{\circ} \mathrm{C}$. Fig. 3 shows the air velocity magnitude and direction in the cooling tower. The air velocity at the cooling tower entrance is 5.5 $\mathrm{m} / \mathrm{s}$, after which it decreases gradually and its direction turns towards the discharge. A recirculation zone generating low air velocity is attached to the left wall of the cooling tower, around the left-most nozzles. In addition to that, the air flow slows down at the bottom right side of the cooling tower, where it turns abruptly upwards. These zones with low air velocity have reduced evaporation rate which negatively affects the cooling tower overall performance. On the other hand, the highest air velocity occurs at the right wall of the cooling tower, around the right-most nozzles, where it hits the walls and turns upwards.

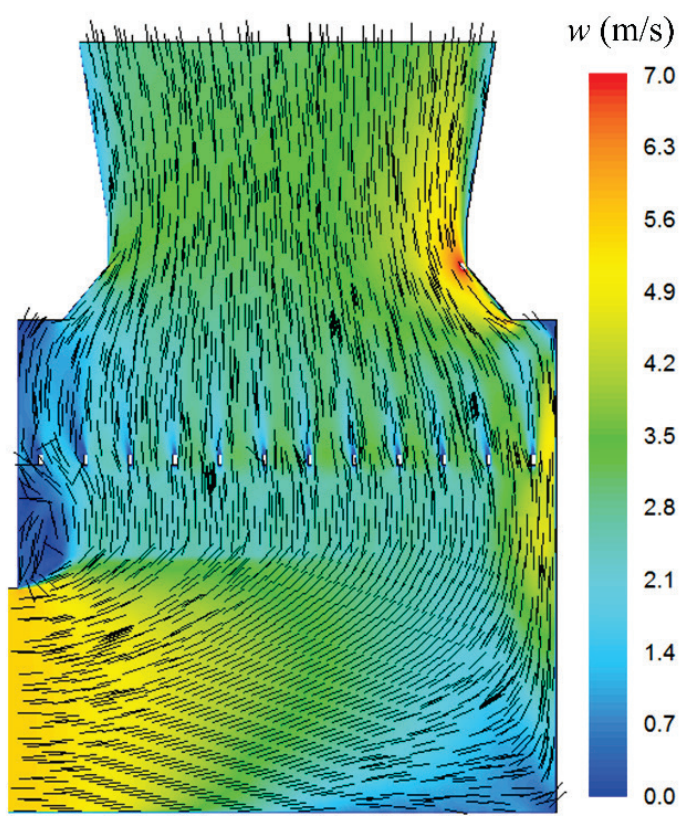

Figure 3 Air flow velocity and direction in the cooling tower

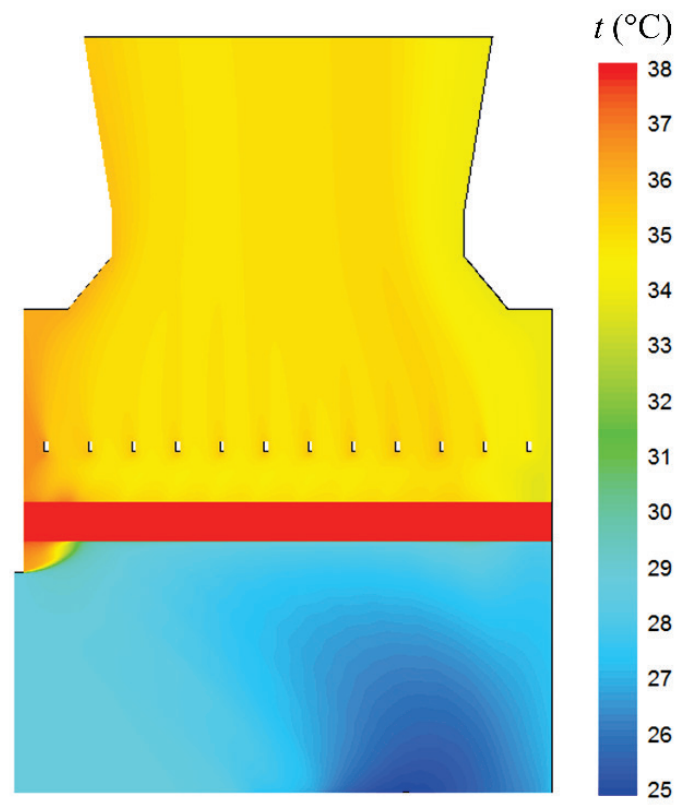

Figure 4 Air temperature in the cooling tower

Fig. 4 shows the air temperature distributions in the cooling tower. The air inlet temperature is $29{ }^{\circ} \mathrm{C}$ and the water inlet temperature is $38{ }^{\circ} \mathrm{C}$. In the region below the filling, air is cooled by a few degrees due to the dominant effect of evaporative cooling. On the other hand, sensible heat transfer is dominant in the filling and air is heated by the warm water droplets and filling surfaces. The mean air temperature at the discharge is $35.1^{\circ} \mathrm{C}$. 


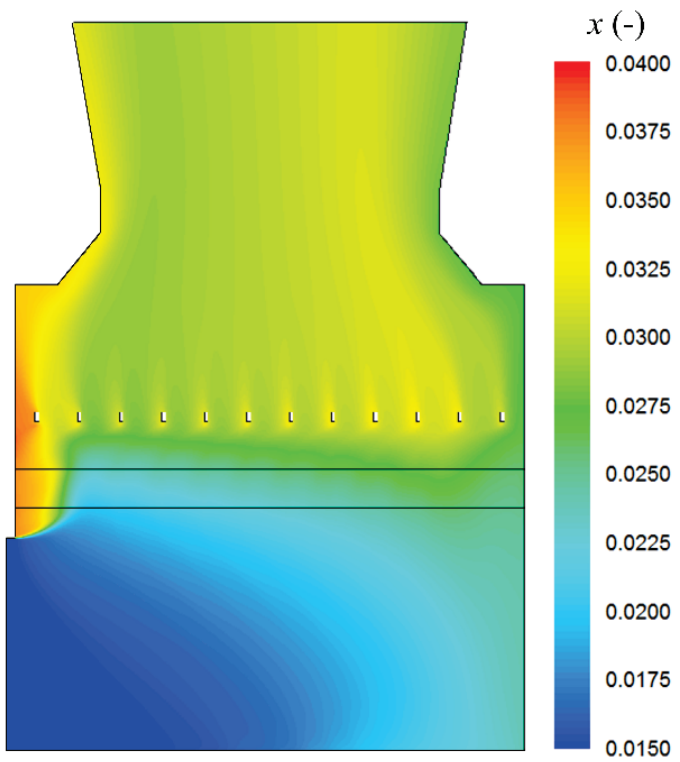

Figure 5 Mass fraction of water vapor in the cooling tower

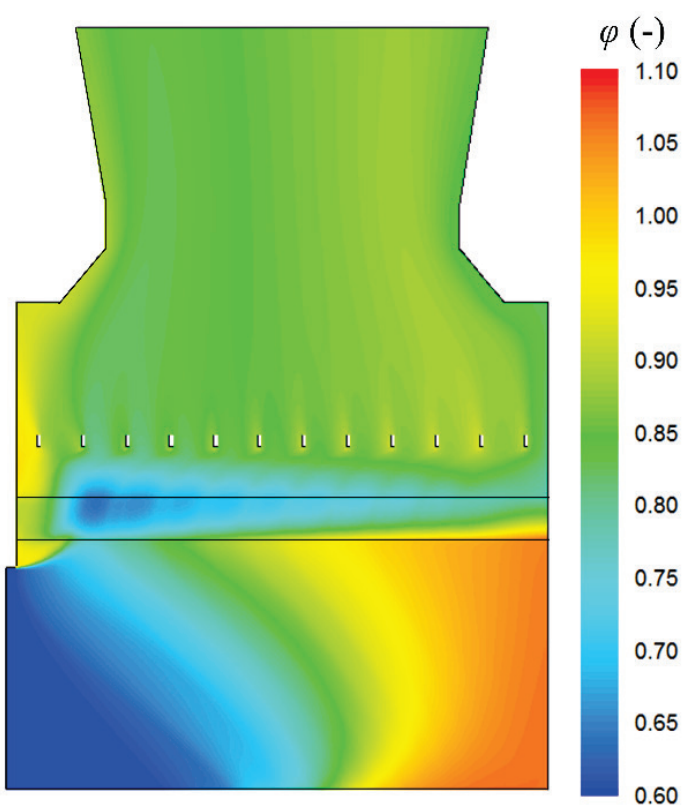

Figure 6 Relative humidity of air in the cooling tower

The mass fraction of water vapor in the gas phase (specific humidity or moisture content, $x$ ) is depicted in Fig. 5. The mass fraction of water vapor at the intake is 0.015 and increases as air flows towards the discharge. The mass fraction of vapor at the discharge is 0.03007 . The highest mass fraction of 0.04 occurs in the recirculation zone attached to the left wall of the cooling tower. Here, air is stagnant and becomes saturated with vapor because of the reduced flow of fresh air. Fig. 6 shows the relative humidity of air in the cooling tower. The relative humidity of air is 0.6 at the intake and 0.86 at the discharge. In the bottom right zone of the tower, the relative humidity of air is greater than 1.0 , which means that air is supersaturated and that water vapor condenses to form droplets.
Fig. 7 shows water droplet trajectories colored by the local rate of evaporation. The droplet trajectories are deflected to the right under the force of the incoming air flow. The rate of evaporation is the highest just below the nozzles and along the trajectories of the droplets. The evaporation rate reduces in the bottom part of the cooling tower as air humidity increases up to the point of saturation.

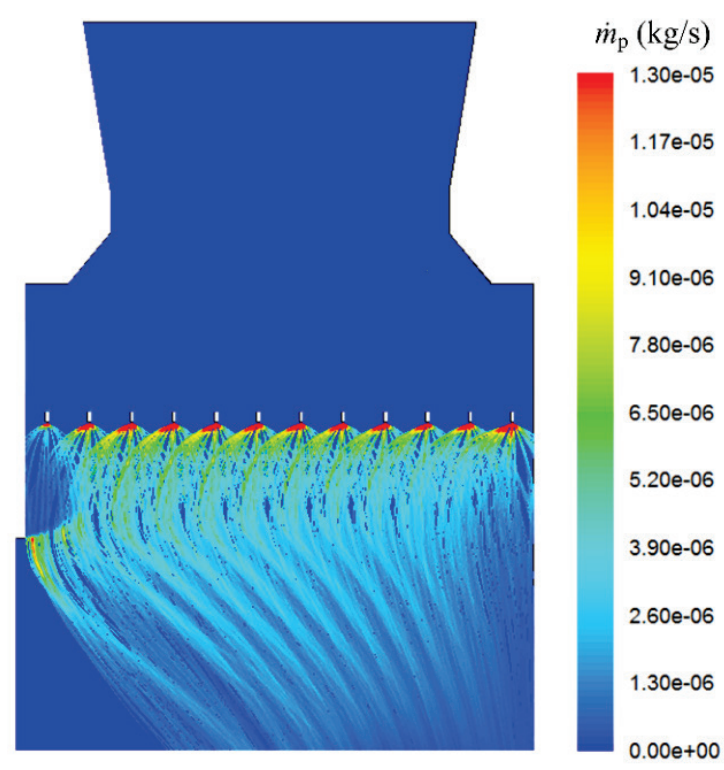

Figure 7 Water droplet trajectories and rate of evaporation

\subsection{Evaporation Loss}

The amount of evaporated water from the cooling tower can be determined using the results shown in Figure 5. The mass fraction of water vapor increases from 0.015 at the intake to 0.03 at the discharge. Thus, the mass of evaporated water per unit of air flow is $0.015 \mathrm{~kg} / \mathrm{kg}$. Taking into account that the air mass flow in the cooling tower is $31.75 \mathrm{~kg} / \mathrm{s}$, the evaporation loss is $0.476 \mathrm{~kg} / \mathrm{s}$. Since the water mass flow rate in the cooling tower is $26.16 \mathrm{~kg} / \mathrm{s}$, the loss of evaporation is $1.82 \%$. The water lost to evaporation must be replaced in order to maintain the cooling tower in steady operation. Usually, wet cooling towers exhibit evaporation losses between $1 \%$ and $2 \%$, as reported by [3].

\subsection{Energy Balance and Efficiency of the Cooling Tower}

The mass balances for dry air and water in the cooling tower are

$\dot{m}_{\text {air, in }}=\dot{m}_{\text {air, out }}$

$\dot{m}_{\text {water, out }}=\dot{m}_{\text {water, in }}-\dot{m}_{\text {air }}\left(x_{\text {out }}-x_{\text {in }}\right)$

The water mass balance (19) accounts for the evaporation losses by taking into account the difference in the mass fractions of water vapor at the intake and discharge. The energy balance of a cooling tower with negligible heat loss to the ambient (adiabatic cooling tower) states that the heat 
content in the inlet streams is equal to that of the outlet streams, that is

$$
\begin{aligned}
& \dot{m}_{\text {air }} h_{\text {air, in }}+\dot{m}_{\text {water, in }} h_{\text {water, in }}= \\
& =\dot{m}_{\text {air }} h_{\text {air, out }}+\dot{m}_{\text {water, out }} h_{\text {water, out }}
\end{aligned}
$$

The increase in the heat content of air is due to the change in sensible and latent heat contents, that is

$$
\begin{aligned}
& \dot{m}_{\text {air }}\left(h_{\text {air, out }}-h_{\text {air, in }}\right)= \\
& =\underbrace{\dot{m}_{\text {air }} c_{\mathrm{p}}\left(t_{\text {air, out }}-t_{\text {air, in }}\right)}_{\text {sensible heat }}+\underbrace{\dot{m}_{\text {air }} r\left(x_{\text {out }}-x_{\text {in }}\right)}_{\text {latent heat }}
\end{aligned}
$$

The unknown in the energy balance is the water temperature at the cooling tower outlet, which can be determined by putting (19) and (21) in (20) and rearranging

$$
\begin{aligned}
& t_{\mathrm{w}, \text { out }}= \\
& =\frac{\dot{m}_{\mathrm{w}, \text { in }} c_{\mathrm{w}} t_{\mathrm{w}, \text { in }}-\dot{m}_{\text {air }}\left[c_{\mathrm{p}}\left(t_{\text {air, out }}-t_{\text {air, in }}\right)+r\left(x_{\text {out }}-x_{\text {in }}\right)\right]}{\left[\dot{m}_{\mathrm{w}, \text { in }}-\dot{m}_{\text {air }}\left(x_{\text {out }}-x_{\text {in }}\right)\right] c_{\mathrm{w}}}
\end{aligned}
$$

The specific heat capacities of air and water are $1006 \mathrm{~J} / \mathrm{kgK}$ and $4179 \mathrm{~J} / \mathrm{kgK}$, respectively. The latent heat of water evaporation is $2420 \mathrm{~kJ} / \mathrm{kg}$ and the water inlet temperature is $38{ }^{\circ} \mathrm{C}$. The air temperature is $29^{\circ} \mathrm{C}$ at the inlet and $35.1^{\circ} \mathrm{C}$ at the outlet. The mass flow rates of air and water are 31.75 $\mathrm{kg} / \mathrm{s}$ and $26.16 \mathrm{~kg} / \mathrm{s}$, respectively. The mass fractions of water vapor in the air at the inlet and at the outlet are 0.015 and 0.3007 , respectively.

From (21), the total rejected heat in the cooling tower is $1352 \mathrm{~kW}$, where the latent heat transfer is $1158 \mathrm{~kW}$ and the sensible heat transfer is $194 \mathrm{~kW}$. Latent heat transfer is the dominant heat transfer method in the wet cooling tower with a share of more than $85 \%$ in the total heat rejection. Now, from equation (22), the water temperature at the outlet is 26.1 ${ }^{\circ} \mathrm{C}$, which is close to the value of $26^{\circ} \mathrm{C}$, reported by the INA fuel refinery [13-14]. It should be noted that the numerical analysis is performed on a cooling tower, which, for convenience, operates with one-sixteenth of the air and water mass flow rates found in the real cooling tower. Therefore, the heat rejection of the cooling tower would be $21.6 \mathrm{MW}$, when working with the real air and water flow rates. The eight-unit cooling tower system would then achieve a heat rejection of $173 \mathrm{MW}$.

The efficiency of the cooling tower is determined as the ratio of the range to the approach temperature differences. The range is the difference between water inlet and outlet temperatures, and the approach is the difference between the water inlet and the wet bulb air temperatures. Therefore, the efficiency of the cooling tower is

$\eta=\frac{t_{\mathrm{w}, \text { in }}-t_{\mathrm{w}, \text { out }}}{t_{\mathrm{w}, \text { in }}-t_{\mathrm{air}, \mathrm{wb}}} \cdot 100 \%$
The efficiency of the cooling tower is $78.8 \%$, taking into account that the wet bulb temperature of air at the intake is $23{ }^{\circ} \mathrm{C}$. For comparison, the real cooling tower has a declared efficiency of $80 \%$.

\subsection{Effect of Operating Parameters}

Several operating parameters in the spray nozzles and inside the cooling tower may have a significant influence on the water temperature at the outlet, on the heat rejection and the efficiency of the cooling tower. Some of them, such as the water droplet size, the nozzle spray angle and the waterto-air flow rate ratio are discussed here. In the previous analysis the values of these parameters were as follows: mean droplet diameter of $1.5 \mathrm{~mm}$, water-to-air ratio of 0.824 , and nozzle spray angle of $135^{\circ}$. The results obtained with those parameters are referred to as referent values.

The effect of the water-to-air flow rate ratio is studied by changing the air flow rate at the cooling tower intake. Fig. 8 shows that by increasing the air flow rate, the water temperature at the outlet decreases. This means that heat transfer in the cooling tower is enhanced and that heat rejection and efficiency are increased, too. For example, decreasing the water-to-air ratio from the referent value of 0.824 to 0.75 causes an increase in the cooling tower efficiency from $78.8 \%$ to $82.1 \%$. This is at the expense of a higher energy consumption in the mechanical fan that now has to move a larger quantity of air.
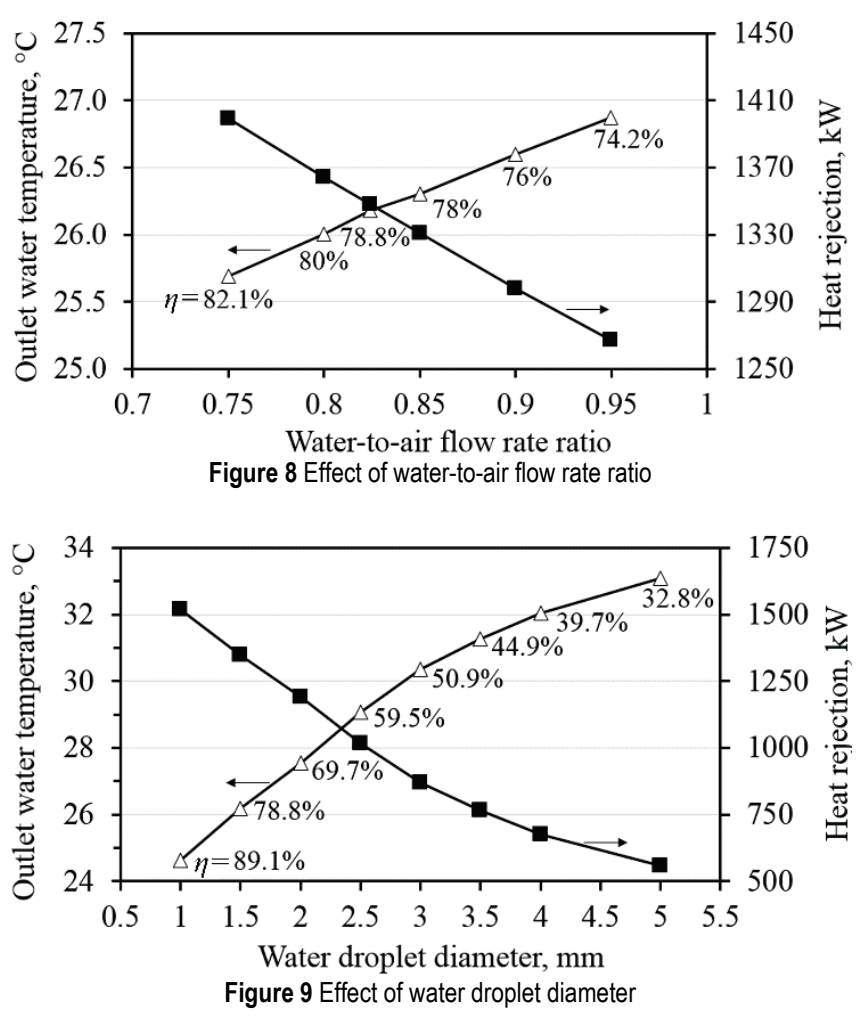

The effect of water droplet size is analyzed by varying the mean diameter of water droplets. As shown in Fig. 9, the water droplet diameter has a dominant influence on the 
cooling tower performance. By reducing the size of water droplets, the water temperature at the outlet decreases while the heat rejection and cooling tower efficiency increase.

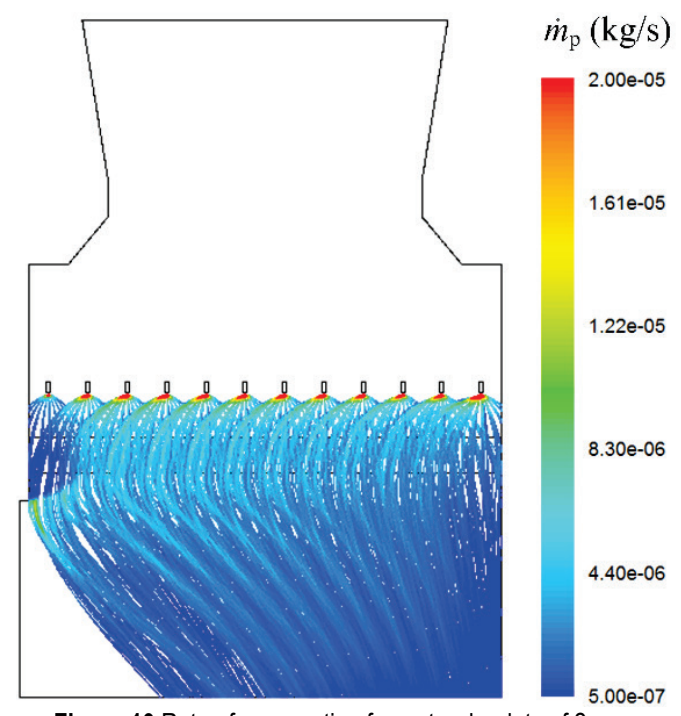

Figure 10 Rate of evaporation for water droplets of $2 \mathrm{~mm}$

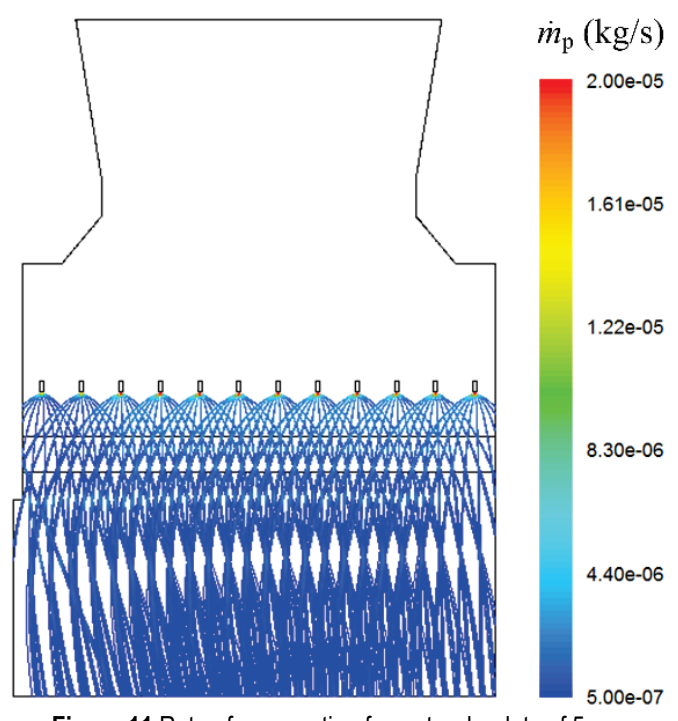

Figure 11 Rate of evaporation for water droplets of $5 \mathrm{~mm}$

Smaller water droplets intensify heat exchange in the cooling tower, especially the latent heat transfer, since the contact surface between water and air is increased. For example, if the diameter of water droplets is halved then the contact surface doubles and the total number of droplets increases eight times for an unchanged water flow rate. The difference in the rate of evaporation arising because of the size of water droplets is shown below. Figs. 10 and 11 show the local rate of evaporation in the cooling tower operating with water droplets having mean diameter of $2 \mathrm{~mm}$ and 5 $\mathrm{mm}$, respectively. The local rate of evaporation is higher for the smaller water droplets. The total rate of evaporation is $0.413 \mathrm{~kg} / \mathrm{s}$ for $2 \mathrm{~mm}$ droplets and $0.144 \mathrm{~kg} / \mathrm{s}$ for $5 \mathrm{~mm}$ droplets. The latent heat transfer is $997 \mathrm{~kW}$ in the first case and $348 \mathrm{~kW}$ in the second case. The cooling tower efficiency is $69.7 \%$ for the smaller droplets and $32.8 \%$ for the larger droplets.

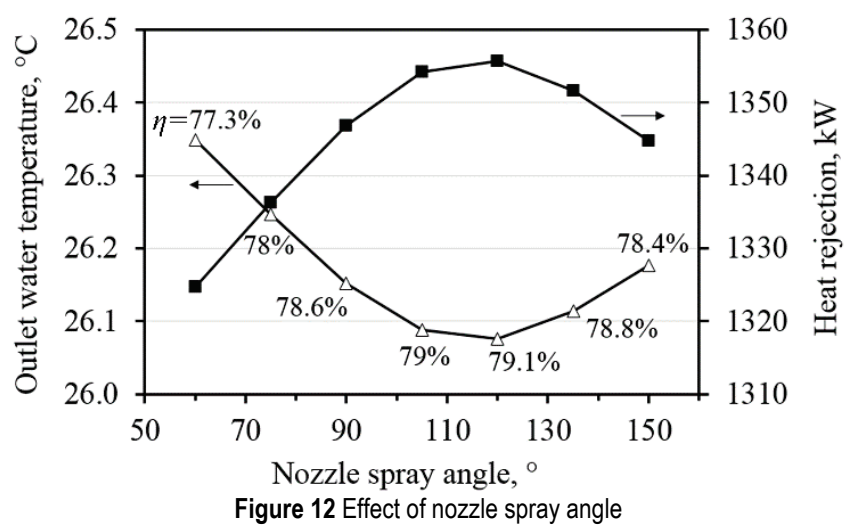

The effect of the nozzle spray angle is shown in Fig. 12. Unlike the water-to-air ratio and the water droplet size, the spray angle exhibits an optimum value across its range of values. This is noticeable at around $120^{\circ}$, for which heat rejection and the cooling tower efficiency are the greatest. The referent spray angle in this study was $135^{\circ}$ and the cooling tower efficiency $78.8 \%$; with a spray angle of $120^{\circ}$ the cooling tower would achieve a slightly better efficiency of $79.1 \%$. Narrow spray angles (less than $70^{\circ}$ ) negatively affect the efficiency of the cooling tower. This is explained by the decreased latent heat transfer, caused by deteriorated mixing between water droplets and air.

\section{CONCLUSION}

This paper presented a numerical study of heat and mass transfer inside a wet cooling tower with forced air draft. The obtained results include the distribution of air flow velocity, air temperature, specific and relative air humidity, water evaporation rates, and water droplets trajectories inside the cooling tower.

The reference cooling tower performance is obtained for water droplet diameter of $1.5 \mathrm{~mm}$, water-to-air ratio of 0.824 and nozzle spray angle of $135^{\circ}$. In that case the efficiency of the cooling tower is $78.8 \%$. The loss of water due to evaporation is $1.8 \%$ in this case. The latent heat transfer is the dominant mode of heat transfer, with a share of $85 \%$ in the total heat rejection of the cooling tower.

The size of water droplets affect significantly the latent heat transfer and the total heat rejection. Smaller water droplets mix better with the air flow and increase the total surface for heat and mass transfer. Consequently, the local evaporation rates and the total heat rejection are also increased. For example, the efficiency of the cooling tower is $89.1 \%$ for an average droplet diameter of $1 \mathrm{~mm}$. Larger water droplets, on the other hand, decrease the evaporation rates and reduce the cooling tower efficiency. It has been seen that the evaporation rates are highest beneath the water nozzles and along the droplet trajectories. The evaporation rates decrease in the bottom part of the cooling tower as air 
humidity increases up to the saturation point. Sensible heat transfer is dominant in the cooling tower filling.

The water-to-air ratio and the nozzle spray angle exhibit weaker effects on the cooling tower efficiency relatively to the water droplet size. The cooling tower efficiency increases with the air flow rate, which reduces the water-to-air ratio. The efficiency is $74.2 \%$ for a water-to-air ratio of 0.95 , and $82.1 \%$ when the water-to-air ratio is 0.75 .

The nozzle spray angle has an effect of less than $2 \%$ on the cooling tower efficiency, over a wide range of values. The maximum cooling tower efficiency is observed for a spray angle of $120^{\circ}$. Narrow spray angles, on the other hand, deteriorate the mixing between the air stream and water droplets and diminish the cooling tower efficiency.

Future research on this subject should expand the present analysis onto three-dimensional cooling towers, including detailed mathematical models and thorough analysis of the parameters affecting the performance of wet cooling towers.

\section{Acknowledgements}

This work has been supported by the Croatian Science Foundation under the project IP-2016-06-4095.

\section{REFERENCES}

[1] Kröger, D. (2004). Air-Cooled Heat Exchangers and Cooling Towers, Thermal-Flow Performance Evaluation and Design. Vol I, PennWell Corporation, Oklahoma.

[2] Kröger, D. (2004). Air-Cooled Heat Exchangers and Cooling Towers, Thermal-Flow Performance Evaluation and Design. Vol II, PennWell Corporation, Oklahoma.

[3] Stanford, H. W. (2012). HVAC Water Chillers and Cooling Towers, Fundamentals, Application and Operation. CRC Press, Taylor \& Francis Group, New York.

[4] Mungan, I. \& Wittek, U. (2004). Natural Draught Cooling Towers, Taylor \& Francis Group, London, UK. https://doi.org/10.1201/b17001

[5] Söylemez, M. S. (2004). On the Optimum Performance of Forced Draft Counter Flow Cooling Towers. Energy Conversion and Management, 45, 2335-2341. https://doi.org/10.1016/j.enconman.2003.11.023

[6] Zunaid, M., Murtaza, Q., \& Gautam, S. (2017). Energy and Performance Analysis of Multi Droplets Shower Cooling Tower at Different Inlet Water Temperature for Air Cooling Application. Applied Thermal Engineering, 121, 1070-1079. https://doi.org/10.1016/j.applthermaleng.2017.04.157

[7] Bourouni, K., Bassem, M. M., \& Chaibi, M. T. (2008). Numerical Study of Coupled Heat and Mass Transfer in Geothermal Water Cooling Tower. Energy Conversion and Management, 49, 988-994. https://doi.org/10.1016/j.enconman.2007.10.003

[8] Jiang, J.-J., Liu, X.-H., \& Jiang, Y. (2013). Experimental and Numerical Analysis of a Crossflow Closed Wet Cooling Tower. Applied Thermal Engineering, 61, 678-689. https://doi.org/10.1016/j.applthermaleng.2013.08.043

[9] Goodarzi, M. \& Keimanesh, R. (2015). Numerical Analysis on Overall Performance of Savonius Turbines Adjacent to a Natural Draft Cooling Tower. Energy Conversion and Management, 99, 41-49.

ttps://doi.org/10.1016/j.enconman.2015.04.027
[10] Zou, Z. \& Gong, H. (2016). Numerical Analysis of Solar Enhanced Natural Draft Dry Cooling Tower Configuration. Applied Thermal Engineering, 94, 697-705. https://doi.org/10.1016/j.applthermaleng.2015.10.141

[11] Smrekar, J., Oman, J., \& Širok, B. (2006). Improving the Efficiency of Natural Draft Cooling Towers. Energy Conversion and Management, 47, 1086-1100. https://doi.org/10.1016/j.enconman.2005.07.012

[12] Xia, L., Gurgenci, H., Liu, D., Guan, Z., \& Zhou, L. (2016). CFD Analysis of Pre-Cooling Water Spray System in Natural Draft Dry Cooling Towers. Applied Thermal Engineering, 105, 1051-1060. https://doi.org/10.1016/j.applthermaleng.2016.03.096

[13] Šoić, I. (2015). Thermodynamic Analysis of Heat and Mass Transfer in a Cooling Tower, Master thesis, Faculty of Engineering, University of Rijeka, Rijeka.

[14] Šoić, I., Blecich, P., \& Franković, B. (October 2016). Termodinamička analiza izmjene topline i prijenos tvari $\mathrm{u}$ rashladnom tornju. Zbornik radova 24. medunarodnog kongresa Energija $i$ okoliš/Proceedings of the $24^{\text {th }}$ International Congress Energy and the Environment, Opatija, 497-508.

[15] Versteeg, H. K. \& Malalasekera, W. (2007). An Introduction to Computational Fluid Dynamics: The Finite Volume Method, $2^{\text {nd }}$ ed., Pearson Education, Essex, UK.

[16] Ranz, W. E. \& Marshall, W. R. (1952). Evaporation from Drops, Part I and Part II. Chemical Engineering Progress, 48, 173-180.

[17] Ergun, S. (1952). Fluid Flow through Packed Columns. Chemical Engineering Progress, 48, 89-94.

\section{Authors' contacts:}

Paolo BLECICH, PhD, Assistant Professor Faculty of Engineering, University of Rijeka Vukovarska 58, HR-51000 Rijeka, Croatia Tel.: +385 51651 543, paolo.blecich@riteh.hr

Tomislav SENČı́́, PhD, Associate Professor Faculty of Engineering, University of Rijeka Vukovarska 58, HR-51000 Rijeka, Croatia Tel.: +385 51651 515, tomislav.sencic@riteh.hr

Igor WOLF, PhD, Associate Professor Faculty of Engineering, University of Rijeka Vukovarska 58, HR-51000 Rijeka, Croatia Tel.: +385 51651 510, igor.wolf@riteh.hr

Igor BONEFAČıć, PhD, Assistant Professor Faculty of Engineering, University of Rijeka Vukovarska 58, HR-51000 Rijeka, Croatia Tel.: +38551651 561, igor.bonefacic@riteh.hr 